Article

\title{
Expectations and limitations of Cyber-Physical Systems (CPS) for Advanced Manufacturing: A View from the Grinding Industry
}

\author{
Iñigo Pombo $^{1}$, Leire Godino ${ }^{1}\left[\right.$, Jose Antonio Sánchez ${ }^{1, *(1)}$ and Rafael Lizarralde ${ }^{2}$ \\ 1 Faculty of Engineering Bilbao, University of the Basque Country (UPV/EHU), Plaza Ingeniero Torres \\ Quevedo, 1, 48013 Bilbao, Bizkaia, Spain; inigo.pombo@ehu.eus (I.P.); leire.godino@ehu.eus (L.G.) \\ 2 IDEKO, Arriaga Kalea, 2, 20870 Elgoibar, Gipuzkoa, Spain; rlizarralde@ideko.es \\ * Correspondence: joseantonio.sanchez@ehu.eus; Tel.: +34-946-014-822
}

Received: 14 July 2020; Accepted: 19 September 2020; Published: 22 September 2020

check for updates

\begin{abstract}
Grinding is a critical technology in the manufacturing of high added-value precision parts, accounting for approximately $20-25 \%$ of all machining costs in the industrialized world. It is a commonly used process in the finishing of parts in numerous key industrial sectors such as transport (including the aeronautical, automotive and railway industries), and energy or biomedical industries. As in the case of many other manufacturing technologies, grinding relies heavily on the experience and knowledge of the operatives. For this reason, considerable efforts have been devoted to generating a systematic and sustainable approach that reduces and eventually eliminates costly trial-and-error strategies. The main contribution of this work is that, for the first time, a complete digital twin (DT) for the grinding industry is presented. The required flow of information between numerical simulations, advanced mechanical testing and industrial practice has been defined, thus producing a virtual mirror of the real process. The structure of the DT comprises four layers, which integrate: (1) scientific knowledge of the process (advanced process modeling and numerical simulation); (2) characterization of materials through specialized mechanical testing; (3) advanced sensing techniques, to provide feedback for process models; and (4) knowledge integration in a configurable open-source industrial tool. To this end, intensive collaboration between all the involved agents (from university to industry) is essential. One of the most remarkable results is the development of new and more realistic models for predicting wheel wear, which currently can only be known in industry through costly trial-and-error strategies. Also, current work is focused on the development of an intelligent grinding wheel, which will provide on-line information about process variables such as temperature and forces. This is a critical issue in the advance towards a zero-defect grinding process.
\end{abstract}

Keywords: cyber-physical systems; digital twin; advanced manufacturing; grinding process; grinding wheel

\section{Introduction and Literature Review}

Digital solutions for improving the performance of high added-value manufacturing industries are paving the way towards the digitalization of industrial companies. Machine-tool manufacturers have taken the lead in the development of tools such as Celos or Savvy [1], which provide excellent platforms for digitalization. Digitalization of the manufacturing sector is running parallel to current societal and economic developments. In a survey conducted in 2020, Eurostat states that the manufacturing sector employed more than 28.5 million people in the EU in 2017 [2], with this sector occupying third place in the employment rankings [3]. CECIMO (The European Association of the Machine Tool Industries), in its annual survey on machine-tool production, states that since January 2017, industrial production 
has grown by 3.0\% in the EU [4], emphasizing the importance of the manufacturing sector in current European society.

With regard to the development of manufacturing technologies in the EU, in a recent survey carried out in 2019 [5], it is stated that "the production processes will become increasingly digital and less mechanical", whilst also pointing out that "Digitisation is expanding possibilities to: design and test products or processes virtually (simulation); repair industrial apparatus remotely; and automate the constant fine-tuning of processes." A recent paper [6], studied in detail the main aspects and technologies that will enable this revolution, along with the main application domains.

The grinding process is key in the manufacturing of high added value parts in many industrial sectors such as aerospace, the automotive industry, and energy production [7]. Its characteristics make it the best choice when smooth tolerances and good surface quality must be achieved in difficult-to-machine materials. This fact is of critical importance in the previously mentioned industrial sectors in which new materials are being developed every day, and the precision requirements continue to become more demanding [8]. Thus, together with high-quality ground parts, the grinding process is required to be highly productive whilst also meeting sustainability demands [9].

Grinding will also play a leading role in facing some of the challenges related to the development of e-mobility (according to Bloomberg NEF, in 2040 there will be more electric vehicles than combustion vehicles), the need to expand aircraft fleets (which, according to the Aerospace and Defense Industries Association of Europe, is a sector that is expected to see considerable growth up until 2032) and the new challenges to be met in terms of ensuring clean and sustainable energy systems [10]. Grinding is adapting successfully to the current situation and, according to a recent report [11], the grinding wheel market is predicted to show an annual growth rate of around $2.83 \%$ until 2025, particularly in the niche market sectors such as those mentioned previously. This fact reflects the industrial importance of the process and highlights the necessity for industrial companies to optimize their grinding processes in order to be competitive in the 21st century global society. In spite of these encouraging data, it is important to note that the global situation of the industry is continuously changing [12] and that grinding technology must be prepared to be competitive within this framework.

Cyber-physical systems (CPS) will be critical for facing these new challenges. The digital twin (DT) concept is now key for optimizing capabilities of manufacturing processes. In [12], this concept is widely analyzed and applied to the manufacturing processes and it has been defined as "a mirror of the real world that provides a means of simulating, predicting and optimizing physical manufacturing systems and processes". Usually, the DT is thought to be the same as a model or a theoretical simulation of a given process, but it is, in fact, much more: A digital twin is a high-fidelity representation of the operational dynamics of its physical counterpart, enabled by almost real-time synchronization between the cyberspace and physical space [13]. In a recent work [14], a digital twin-based design platform was validated with a case study of the hollow glass smart manufacturing system. The application to lean production is addressed in [15], comparing the performance of three pull control strategies by simulation. In both cases results prove the efficiency of the approach. However, no references have been found to put the focus on the process itself, which is particularly critical in the case of the grinding industry.

The selection of the grinding process is based on the fact that it is one of the most complex machining processes, that involves a large number of variables that, to some extent, cannot be directly controlled. For instance, tool wear in milling or turning is a well-known fact, with good predictive models being currently available. It is also possible to know tool wear in turning or milling by using a pre-setting tool station. However, the mechanisms of wheel wear in grinding are extremely complex because of the composite nature of the grinding wheel. In fact, wheel wear is only indirectly known in grinding, because of its effect on part damage. Also, problems such as grinding burn (because of excessive contact temperatures) do not affect turning or milling. Many other aspects such as part finishing, spark-off operations, etc. can be also cited. In summary, grinding is more heavily based on 
experience than other machining processes, for which models are available; therefore, it is an optimal technology to test the impact of digital twins in the machining industry.

According to this, a number of elements must be included within a DT such as process modelling, the characterization of grinding wheel mechanical behavior, and process monitoring.

\subsection{Process Modelling}

Process modelling is a classic research topic. One of the most popular modelling areas concerns the thermal aspects of the grinding process due to their importance for impacting process performance. In the 1970s Malkin and Anderson [16] developed the first systematic analysis of the thermal elements of the grinding process, including simple analytical models based on classic heat conduction mathematical solutions. Several analytical developments were made by various authors such as Snoeys et al. [17], Lavine et al. [18,19], Ueda et al. [20], Rowe et al. [21,22], or even in the subsequent works of Malkin et al., summarized in [23]. The most recent research investigations into modelling the grinding process have usually been based on numerical methods because these have a greater capacity to represent reality in comparison with analytical approaches. In this case, these methods are not only focused on thermal issues [23,24], but also on the characterization of material removal mechanisms [25,26], dressing process performance [27] or methods to advance wheel surface modelling [28]. Doman et al. [29] conducted a complete review of the most recent advances in grinding modelling. Although not a very recent study, it perfectly summarizes the work that has been done, along with the work that needs to be carried out in the future. The development of sound models for the grinding process is of critical importance, because they allow a deeper understanding of the physical phenomena and the interactions among complex process variables. However, it is a fact that process models commonly fail when they are transferred to industrial workshops. In many cases, the causes for this situation is the complexity of the models (that limits their practical application) and the lack of actual real-time information of the machine and the process. Because of this, integration of such models in industrial practice requires a new and complete approach.

\subsection{Wheel Characterization}

When developing a theoretical model of a real phenomenon, one of the key issues is the characterization of the behavior of the modelled object. Classic models focus on the ground part and traditional metal characterization methods are employed to characterize both thermal and mechanical properties. Whilst this characterization is very useful for analyzing the influence of the process parameters on the ground part, on several occasions this information is shown to be insufficient, such as, for example, when wheel wear needs to be modelled or the behavior of a single abrasive grain must be reproduced. In spite of the importance of characterizing the grinding wheel mechanical behavior (e.g., for a wheel wear model) relatively few studies have addressed this issue. In regard to including material characteristics in the models, Young's modulus is used to characterize the elastic behavior of the wheel. This classic approach involves associating the hardness of the wheel with its Young's modulus [30]. However, classic studies suggest that this hypothesis is not completely correct [31] and using the same grade for different wheels can lead to variations in Young's modulus values. There is a lack of knowledge about this important issue in wheel modelling. Additionally, relatively few studies can be found regarding the fracture behavior of the grinding wheel. Given the nature of the grinding wheel structure, it should be regarded as a quasi-brittle material. In recent years, various research groups have focused their efforts on developing discrete element method (DEM) solutions to characterize the fracture behavior of these types of materials [32-34] Furthermore, in $[35,36]$ the authors characterize the fracture behavior of the grinding wheel using a DEM model, they propose an experimental procedure for quantifying mechanical parameters (Brazilian test applied to grinding wheels) [35], and they describe tests for characterizing the grinding wheel material [36]. Unfortunately, this approach has not been validated for the classical problem of wheel wear. It is 
therefore not possible to know if the models developed for the bond material correctly represent the wear behavior of the wheel. Extensive work must still be done in this direction.

\subsection{Process Monitoring}

In the case of the grinding process, this is a complex issue due to the characteristics of the process, including accounting for the small contact area between the tool (grinding wheel) and the ground part, high temperature gradients in the contact region (103-104 K/s) [37], poor accessibility to the contact zone, and the large quantity of grinding fluid over the working zone [23]. The easiest parameter to be acquired is the power consumption of the grinding wheel spindle during the process. Although this is a very useful parameter, it only reveals a relatively limited amount of information about the process; thus additional sensors must be used in order to extract useful data from the process. In this regard, a number of attempts have been made to measure grinding temperatures, in both classic and new research works. In particular, the first attempts to measure temperatures with thermocouples were carried out in the 1950s [38], but until the 1990s no reliable data were extracted [39]. Later, several developments were reported in various studies [40,41] —every thermocouple solution presents an unsolvable problem, that is, the difficulty in following the high temperature gradients in the grinding zone. In [42] a state-of-the-art classification of the thermal measuring devices used and methods for material removal processes are presented. Considering these issues, a recent study by Urgoiti et al. [37] developed a new two-color pyrometer-based optical fiber system for measuring the temperature of the ground part. In [43] a new possibility was proposed for the in-process measurement of workpiece temperature in cylindrical grinding. This last work, together with [44], in which the authors propose wireless data transmission, could form the basis of future temperature acquisition devices. Whilst the reviewed studies indicate that considerable efforts have been made to accurately measure the grinding temperatures, there is no suitable technology for implementing this process in an industrial setting. The importance of this issue is shown in [45], where a complete review was carried out on the detection of grinding burn. Moreover, in their work, Teixeira et al. [46] propose an additional method for detecting thermal damage in ground parts, which reinforces the current need for thermal monitoring within the industry.

Another interesting parameter to be measured is wheel wear-traditionally defined by the G-ratio-which represents the volumetric wear of the grinding wheel compared with the amount of ground material. Although the information provided by this parameter is quite useful, again, additional information about the evolution of the grinding wheel surface characteristics is required for a full evaluation of the process performance. There have been considerable developments in recent years in optical devices and software analysis [47-50] for evaluating the evolution of wear flat, and usually the percentage of apparent wear flat area has been used as the wear parameter [23]. In [50] an example of an image analysis application for detecting abrasive grain wear flat was presented. Several attempts have been made to analyze the wear of new types of abrasives [51], which is a key issue in the profile of modern grinding processes [52]. According to the works analyzed, in-machine wheel wear measuring devices will be a fundamental aspect to be studied in future research works, particularly for heavy-duty profile ground parts such as those to be analyzed in this project proposal.

It is also important to analyze the dynamic control of the grinding process. The influence of the dynamic behavior on the quality of the ground part is quite important, since this is the main factor responsible for the appearance of leads and micro leads in the ground surface, or the presence of long wavelength surface marks. When analyzing dynamic behavior, the main problem to arise concerns the difficulty to position the accelerometers near to the grinding zone, which limits the possibility of achieving a highly accurate analysis, particularly when there is a need to analyze low amplitude vibratory phenomena. Several works can be found in the literature, particularly in relation to the avoidance of vibratory effects such as chatter [53-56] and the appearance of surface marks [56,57]. Accelerometers are still usually positioned relatively far away from the contact point between wheel and 
workpiece. Research work and technology development must be done to try to analyze displacement, velocity and acceleration as close as possible to the contact zone.

Finally, in the field of process monitoring, acoustic emission analysis is worth noting; it represents a powerful tool for extracting information about the performance of the process. In [58] a review was conducted of studies regarding acoustic emission during monitoring of the grinding process. Although this review is quite old, recently published works show that the use of acoustic emission in grinding is a very useful tool to monitor the state of wheel wear [58], dressing tool behavior [59] or the avoidance of thermal damage [60].

Analysis of the state-of-the-art and of the needs of the current grinding industry showed that DT technology could be a very powerful tool to analyze, design and optimize industrial grinding processes [12]. In [61], the authors made the first attempt to use a DT applied to the grinding process, which focused on minimizing the environmental impact of the process by analyzing the wheel dressing cycles. However, in this work there is not concern for critical issues such as wheel wear, occurrence of part damage because of grinding burns, etc. It is therefore, a very limited approach to the complex technology of grinding.

The main contribution of this work is that, for the first time, a complete digital twin (DT) for the grinding industry is presented. The required flow of information between numerical simulations, advanced mechanical testing and industrial practice has been defined, thus producing a virtual mirror of the real process. The underlying hypothesis is that process knowledge is distributed between very different agents (wheel manufacturer, machine-tool builders, end-users of the process, and fundamental research groups), and it is necessary to effectively share this knowledge. The aim is to produce a virtual mirror of the real process, integrating innovative monitoring systems (intelligent grinding wheel) and original theoretical and experimental approaches for the grinding processes. First, the local ecosystem in which the DT is being developed is presented. Section 3 presents the global structure of the DT. This structure integrates four different high-tech layers. Each layer is described in detail, and interactions between the layers are discussed. In this paper, an open platform is proposed that is capable of integrating the knowledge generated in the other layers, thus becoming the actual user interface of the DT.

\section{A Local Ecosystem for a Viable DT for the Grinding Industry}

The development of a transferable DT for industry can only be accomplished with the participation of all agents involved in the research, development and industrialization of the technology. This section describes the umbrella under which the concept of a DT for the grinding industry will be developed. The DT is being developed in the Basque Country under the initiative of the Basque Digital Innovation Hub (BDIH). The BDIH is a connected network of advanced manufacturing assets and services infrastructure available to companies for training, research, testing and validation. This initiative offers technological solutions, primarily for SMEs (Small and medium-sized enterprises), in order to meet the challenges of Industry 4.0. To this end, a digitally linked network is created, which consists of a public-private collaboration involving R\&D infrastructures, pilot plants and specialized know-how in different areas of advanced manufacturing. The aims of the network are to develop R\&D projects, the scaling of industrial projects, and the exhibition of cutting-edge technologies, whilst also serving as a resource for training and acceleration of start-ups.

The BDIH is divided into six work areas that are classified according to knowledge and technology, among which the Smart and Connected Machines-Digital Grinding Node is particularly noteworthy. Grinding is a critical manufacturing process which combines the technological complexity of the process with the high demand for quality and fine precision of the process. Moreover, grinding is usually the last process in the manufacturing chain, which ensures the final quality of the manufactured parts. In the Basque Country there are numerous companies that use the grinding process, along with many grinding machine manufacturers. Therefore, in research centers and universities, various research groups are focused on grinding, including the Grinding Process Research Group (UPV/EHU) and the 
IDEKO technological center. In this sense, the mission of the Digital Grinding Node is to collect and coordinate the knowledge and assets of the main agents that develop their activity in the areas of knowledge associated with grinding. Thereby, the Digital Grinding Node forms a multidisciplinary distributed space in which Basque companies_-particularly SMEs—can find solutions to their concerns and needs for knowledge; the companies can take advantage of numerous developments within the field of grinding that cover its multiple variants, including cylindrical, surface, centerless, vertical, and horizontal grinding, and different types of workpiece materials, grinding wheels, and coolants.

\section{A Proposed Transferable DT for the Grinding Industry}

Due to its heavy dependence on non-systematic knowledge, which means that the process relies on extensive trial-and-error strategies, the grinding sector needs to advance towards a complete, transferable and ready-to-use digital twin (DT) through the integration of advanced models of the grinding process, original simulative mechanical tests, and state-of-the-art process sensors.

Since at present grinding technology is linked to high-added value products and markets (e.g., the aerospace, automotive, and railway sectors), by achieving this goal grinding companies (machine-tool builders, wheel manufacturers and end-users of the process) will directly benefit from zero-defect production strategies and reduced setup times in a process that is highly dependent on trial-and-error experimental approaches.

The present work proposes a down-top approach composed of different layers of the DT. The underlying hypothesis is based on the fact that process knowledge is distributed between very different agents (wheel manufacturer, machine-tool builders, end-users of the process, and fundamental research groups), and it is necessary to effectively share this knowledge. The aim is to produce a virtual mirror of the real process, integrating innovative monitoring systems (intelligent grinding wheel) and original theoretical and experimental approaches to grinding processes. The structure of the DT is composed of four layers, which integrate: (1) scientific knowledge of the process (advanced process modeling and numerical simulation); (2) characterization of materials through specialized mechanical testing; (3) advanced sensing techniques, to provide feedback for the process models; and (4) knowledge integration in a configurable open-source industrial tool. Each layer is described in detail in the following paragraphs, while Figure 1 illustrates the general concept underlying the DT.

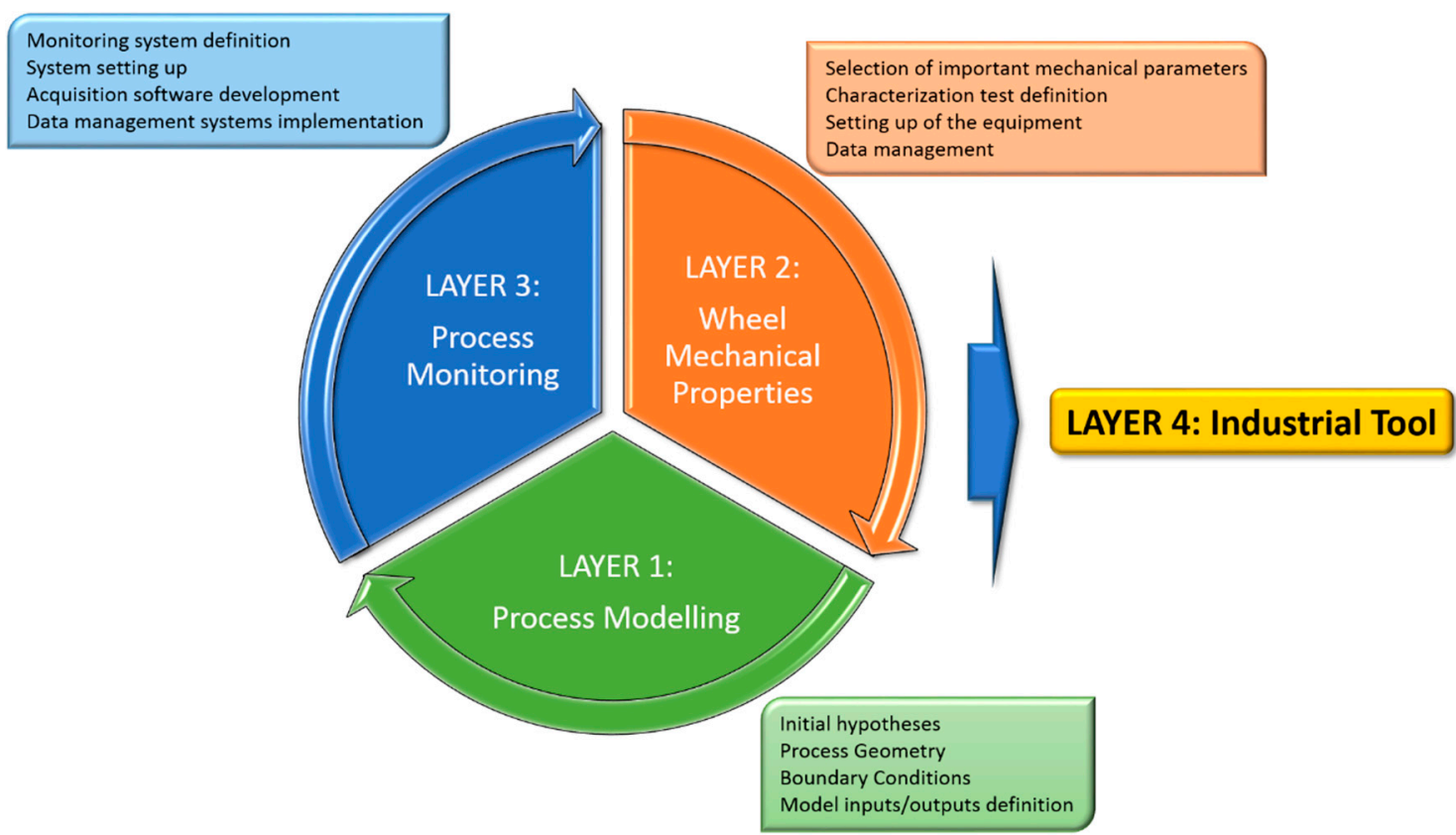

Figure 1. Structure and interaction between layers in the digital twin (DT) for the grinding industry. 


\subsection{Layer 1: Numerical Modeling of Mechanical Behavior of the Grinding Wheel Using Advanced Process Simulation}

One of the main reasons for the lack of systematic knowledge about the behavior of the grinding process itself, and in particular, the behavior of the abrasive tool (the grinding wheel) lies in the fact that grinding wheels are manufactured by mixing abrasive and bonding agents along with certain other components. Since the specification is not fully standardized, and there are no standard mechanical tests for wheel characterization, the result is that it is very difficult to predict the behavior of a grinding wheel for a given part. Although general rules can be followed, the industrial practice of leading wheel manufacturers (Tyrolit, Saint-Gobain, etc.) for the optimum selection of a grinding wheel is absolutely dependent on each specific application. Due to this fact, wheel manufacturers are continuously developing new types of grinding wheels, mixing different grain shapes and sizes, inducing porosity in an artificial way or changing the bonding material properties in order to meet the requirements of new materials to be ground. The development of adequate grinding wheels is particularly important when profile wheels must be used. In this case, whilst it is possible to find not only an optimal material removal rate and good surface quality, it is also important to take into account minimum volumetric wear of the wheel in order to achieve optimal geometrical accuracy. Although this is one of the biggest challenges faced by the current industrial environment, very little information can be found in the scientific literature regarding the link between grinding wheel characteristics and performance. Consequently, in industrial practice, extensive trial-and-error experiments must be carried out in order to determine the optimum parameters for a given application.

In order to meet this challenge, scientific process models can be considered as the deepest layer of a DT of the process. As shown in the literature review, a number of different theoretical models of the process are available. Unfortunately, few of these can be generalized to industrial practice due to the unique specifications of each grinding wheel structure. Thus, a model of the process must consider the interactions between the different components of the grinding wheel, namely abrasive grits, bonding agents, and porosity, along with the interaction between the grinding wheel and the part to be machined.

In the present study, the discrete element method (DEM) has been selected as the optimum numerical tool for the modeling and simulation of the grinding process. DEM models allow for reproducing the granular structure of the grinding wheel and the mechanical behavior of the bonding bridges. Likewise, the development of cohesive beam models allows for the simulation of continuous bodies using DEM [62]. The mechanical properties of the bonding agent can be replicated at a microscopic level in such a way that the complete behavior of the wheel body can easily be reproduced, regardless of its composition. The interactions with the part material can also be modelled; by doing so, it is possible to predict critical process data such as the contact forces, temperatures and power consumption. The effect of wheel rotation can also be included in the model, which is an interesting contribution, particularly for high-speed grinding processes. These possibilities are supported by preliminary investigations conducted by our research group, such as those published in $[63,64]$. Nonetheless, intensive research is currently being carried out to optimize DEM models and their application to the DT of the grinding process. Figure 2 shows a DEM model of a high-performance alumina grinding wheel. This model is being developed in collaboration with the wheel manufacturer UNESA (Abrasivos UNESA, S.A.,Hernani, Spain) and the ENSAM of Bordeaux. In the present DEM model the real grinding process is modelled. To this end, not only real grinding parameters are considered, but also the composition of real grinding wheels. Firstly, a discrete grinding wheel is built in order to characterize the mechanical behavior of the wheel, especially the behavior of the bond. To this end the size of the discrete elements (DEs) are equal to the real abrasive grain, $350 \mu \mathrm{m}$. This hypothesis allows the isolation of a bond fracture from the other types of wheel wear. In order to minimize the computational cost of the model, instead of modelling the real grinding wheel, which has an actual diameter of $400 \mathrm{~mm}$, a wheel with a reduced diameter of $30 \mathrm{~mm}$ is modelled. Likewise, the width and thickness are also reduced, and are modelled with a width of $5 \mathrm{~mm}$ and a wheel thickness 
of $10 \mathrm{~mm}$. The modification of the external diameter of the grinding wheel also affects different process parameters, such as the grinding wheel speed or the contact length, therefore the corresponding parameter correlations are also performed. Moreover, the real contact length and the real contact time is considered in the DEM model, therefore, a specific workpiece shape is designed. Finally, the real force generated during grinding is introduced in the model with the aim of reproducing the mechanical behaviour of the grinding wheel during the grinding process.

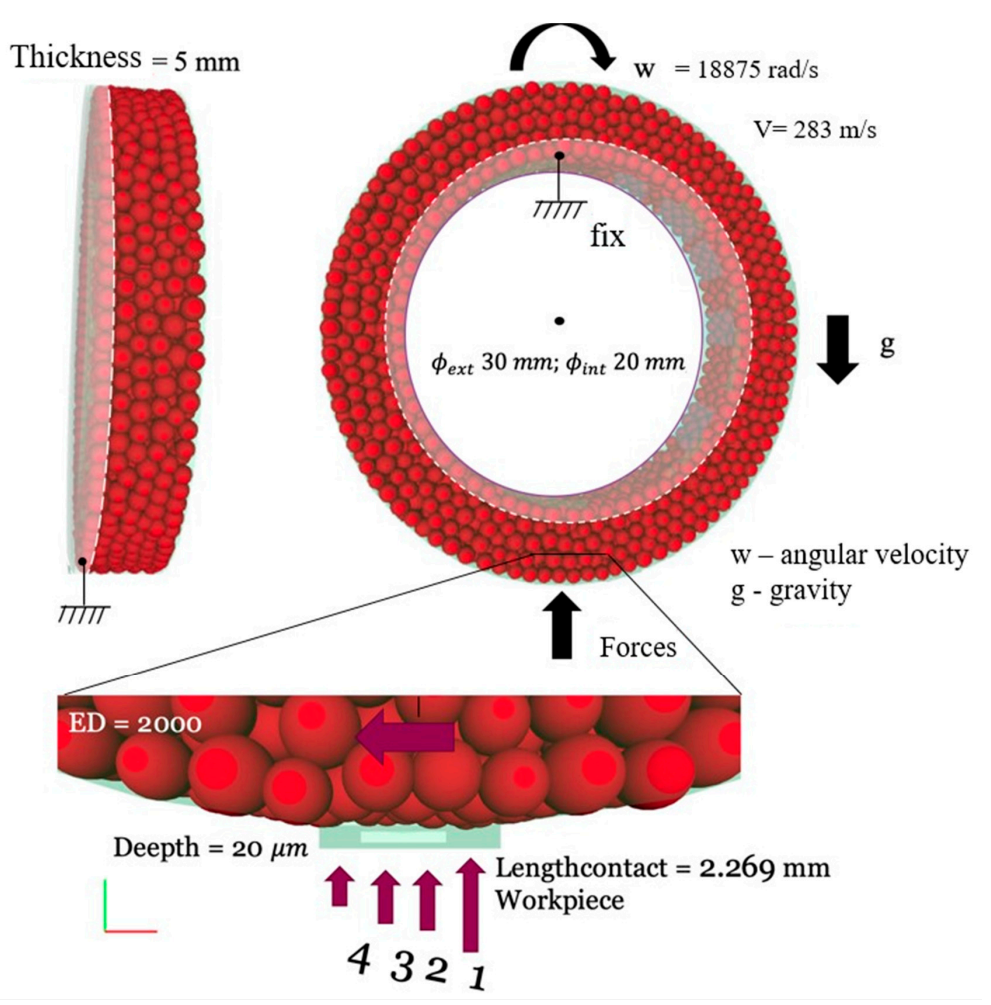

Figure 2. The discrete element method DEM model of a high-performance alumina grinding wheel.

Layer 1 only makes sense by interacting with the rest of the elements of the digital twin. Thus, mechanical characterization of the properties of both the bonding agent and the abrasive grits requires the development of advanced and specific mechanical tests for the wheel, which is considered a quasi-brittle material. Layer 2 focuses specifically on those tests (see below), and the knowledge generated in Layer 2 must immediately be made available to the DEM models that constitute Layer 1. Moreover, the model can also be fed with actual data inputs from the industrial process (see Layer 3 in this Section). Finally, the DT must address the classic problems of computationally heavy numerical models, which are barely applicable to production-oriented industrial workshops. The integration with Layer 4 is therefore a key issue for the DT.

\subsection{Layer 2: Advanced Testing for Mechanical Characterization of Alumina Grinding Wheels}

As previously mentioned, one of the drawbacks for mechanical characterization of grinding wheels is their composition. The wheels are composed of abrasive grains, bonding agents and pores, and each of these elements have different mechanical properties. Moreover, during grinding wheel manufacturing, high temperatures are reached, which also modifies the mechanical properties of the body. Whilst there are studies in the literature that have conducted in-depth analyses to determine the mechanical properties of abrasive grains, there is no consensus regarding the values of such properties. Moreover, the most recent trend has been to manufacture customized grinding wheels depending on the particular needs of each case. Thus, for each application, there are differences in abrasive and bonding materials and grain shape and wheel porosity, which hinders establishing a common 
characterization of grinding wheels. Therefore, following a review of the literature regarding the mechanical properties and behavior of grinding wheels and composites, it is concluded that the best option is to characterize the mechanical behavior of these grinding wheels as a concrete, and thus, quasi-brittle material.

Quasi-brittle materials show a nonlinear response, combining a moderate strain hardening (which is a characteristic of metallic materials) with sharp softening responses representative of brittle materials. With regard to the behavior of the wheel binder during grinding, among the various mechanical properties, particular attention is paid to the ultimate principal tensile strength $\sigma_{\max }$ which will be used as an input parameter in the DEM model proposed in Layer 1. Likewise, Young's modulus E and the Poisson coefficient $v$ are the two other input mechanical properties in the DEM model. The development of precise experimental methods for determining these variables also becomes a primary objective when developing the DT of the process. The behavior laws of the grinding wheel material, assumed to be a quasi-brittle material, must be determined by mechanical tests such as the Brazilian test, which is described in the following paragraphs.

In the reviewed literature, the Brazilian tests are carried out using a disk, as shown in Figure 3a. However, this specimen configuration does not take into account the shape of the grinding wheel, which has a central hole. Moreover, the shape of the specimen determines the beginning of crack propagation. Therefore, new specimens are designed and manufactured as shown in Figure $3 b$. The specimen presents a central hole and flat surfaces to secure the specimen and to impose the load.

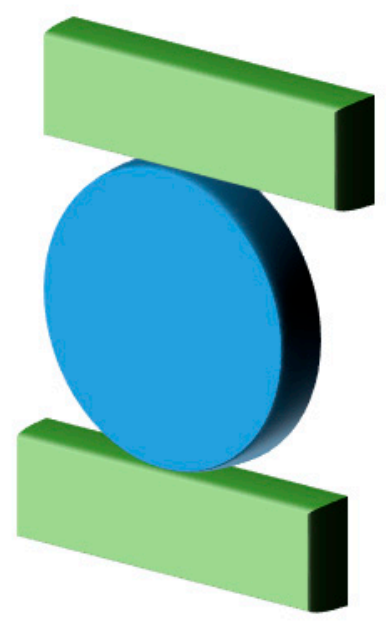

(a)

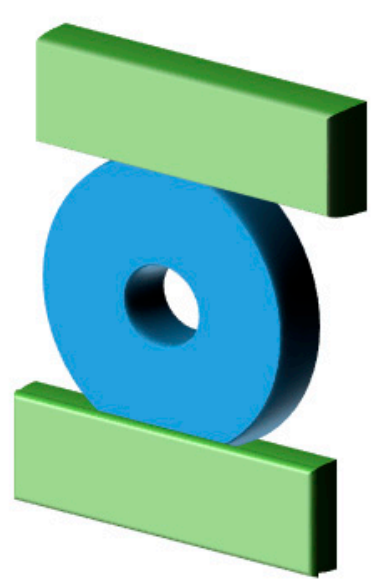

(b)

Figure 3. A disk specimen configuration used for (a) conventional Brazilian tests and (b) modified Brazilian tests.

The modified Brazilian tests need to include digital image correlation (DIC) analysis and fractography in order to thoroughly analyze crack propagation together with the quantification of ultimate principal tensile strength $\sigma_{\max }$. The values of ultimate tensile strengths varied between 60 and $85 \mathrm{MPa}$ for the different specimens that were tested. The values were archived, as this information is critical for feeding the DEM simulation model presented in Layer 1. The ultimate tensile strength determines the fracture of the bonding agent and thus the wear of the grinding wheel.

\subsection{Layer 3: A New Generation of Grinding Process-Monitoring Systems: Intelligent Grinding Process}

Numerical models (as described in Layer 1) and simulative testing (Layer 2) are fundamental for obtaining a better understanding of the grinding process. However, these are more strongly related to the scientific knowledge of the process and do not allow for efficiently considering a large number of weaker interactions related to actual machining. Some examples of these interactions in the grinding 
process include the influence of the workpiece holding, the effect of coolant flow, and the presence of vibrations. Eventually, extremely complex and heavy process models could incorporate these types of effects, but then the industrial applications would be even more limited. To solve this problem, a digital twin must be able to collect actual and in-process information about process variables and incorporate this information, in order to update existing models.

Due to the nature of the grinding process, current instrumentation is very limited. The interaction between wheel and workpiece occurs at very high contact speeds (in many cases, higher than $100 \mathrm{~m} / \mathrm{s}$ ), with extremely high local contact pressure (1-2 GPa), whilst generating local temperatures close to the melting temperature of the component material. In this case, temperature gradients are extremely steep, which makes the process of temperature measurement very difficult.

All these problems must be addressed by the DT of the grinding process. Intensive research work is being conducted to set up advanced instrumentation that can provide the existing models with useful information. Thus, power measurement has already been implemented in grinding machines, and the information collected was made available to the user through the GREAT software (see Layer 4). Since too high a contact temperature may ruin an expensive component, a sensorized grinding wheel is currently being developed for actual temperature measurement. This wheel will use two-color pyrometry and a wireless connection with Layer 4, so that the machine user can access real-time information about the effect of grinding temperatures on the component being manufactured. Sensors are also being developed to control the dynamic behavior of the wheel. In this case, the use of virtual sensors could represent a potentially interesting alternative if combined with artificial intelligence models from which useful indicators can be extracted. Finally, optical sensors for the control of wheel effective topography and contact conditions will also be integrated in Layer 3, including micro cameras and image recognition software to identify both volumetric wear and the appearance of wear flat in abrasive grains.

\subsection{Layer 4: Grinding Research Assisting Tool (GREAT)}

Computational models of the process, such as those described in Layer 1, provide a more in-depth understanding about the large number of interactions among process variables. However, these types of simulations are time-consuming, and usually require high-performance hardware to run and speed up the model computations. These factors drastically limit the industrial application of scientific models. Moreover, the use of platforms such as the previously mentioned GranOO (which is not a commercial software) requires trained and specialized researchers that can define the boundary conditions and simplify hypotheses. Clearly, this is not easily achievable in a machine-tool workshop.

With the aim of integrating all the developed knowledge within an instrument that can be used on the shop floor, an intuitive and easy-to-use software tool is being developed. The software, called GREAT (Grinding Research Assisting Tool, Figure 4) is already in its first version, and incorporates only a limited number of apps that help the user in the task of process optimization. The apps developed are listed here:

- Power acquisition

- Power analysis

- Specific energy analysis

- Power consumption predictor

- Grinding burn analysis

- Wheel-material data base

- Wheel wear measurement

- Dresser wear measurement 


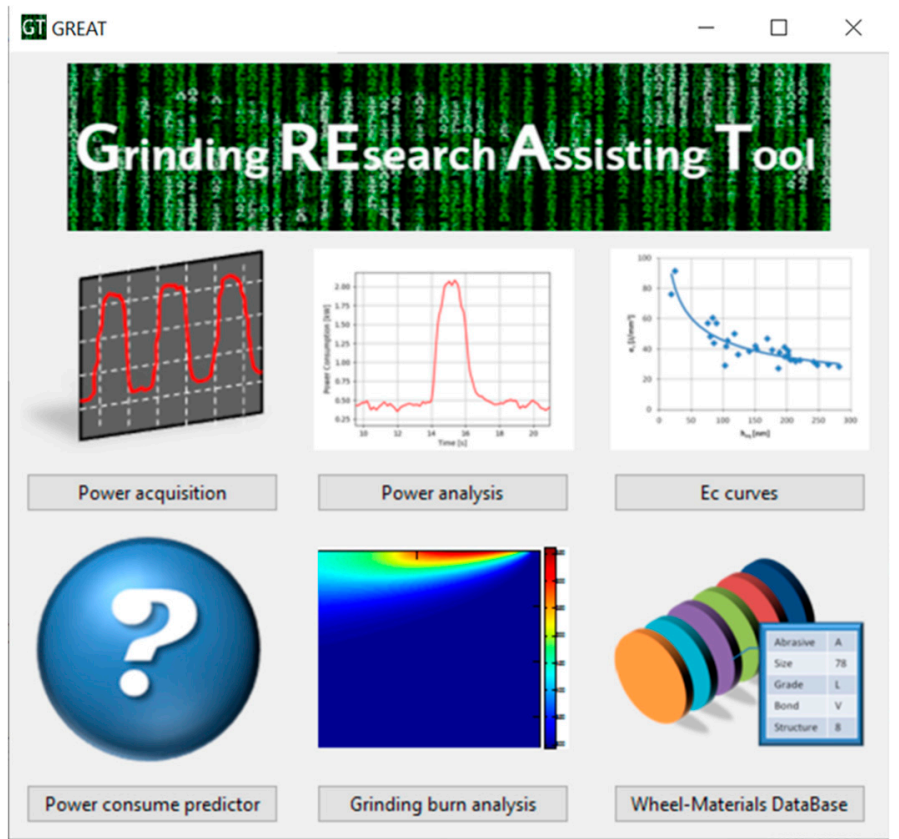

Figure 4. Layer 4: The Grinding Research Assisting Tool (GREAT).

GREAT is being developed in Python, and it is based on a simple user-interface that assists the user during grinding operations. In order to do so, the results obtained from numerical models developed in Layer 1 must be converted into a set of tables and equations that will be stored in the wheel-material database (see Figure 4). Data for the specific grinding wheel are fed from Layer 2. The reduced models are correlated with the current grinding operation through the interaction with Layer 3, since the GREAT software must be able to receive data from the different sensors implemented both on the machine and on the grinding wheel. Thus, at the current stage it is possible to integrate actual power consumption data (power acquisition module in Figure 4). Since the software is open and completely scalable, in the near future it is anticipated that data from temperature sensors, force gauges, accelerometers and other advanced instrumentation will be included. Moreover, one of the advantages of this software is the developed user-friendly interface, which is intuitive and easy to use. This feature makes GREAT a suitable tool for both industrial and academic environments.

It is worth noting that the DT is not a static concept. As new grinding apps are continuously optimized, they will be incorporated into the DT and updated in GREAT. In this regard, GREAT is also conceived as an open user interface. Existing knowledge will be presented in a user-friendly application, although the scientific fundamentals can be complex and deep, as explained in Layers 1 to 3. For instance, it is expected that new modules for wheel wear quantification (based on optical sensors to be developed in Layer 3), measurement of the mechanical properties of the wheel (to be developed in Layer 2), monitoring of dressing devices (to be developed in Layer 2), and others will become available and incorporated in the near future. Finally, the aim is to have a "cloud system" accessible to the end user via the internet so that they are able to receive assistance according to their particular needs.

\section{Conclusions}

This paper presents a general approach to the development of a digital twin that can be effectively applied in the grinding industry. In view of both the existing knowledge and advances in technology, the following conclusions can be drawn:

- If the DT is to be useful for industry whilst serving as a virtual mirror of the manufacturing process, interaction between industry, applied research and fundamental research is essential. This means that industrial companies, research centers and university groups must share 
knowledge, facilities and case studies for the application. The Digital Grinding Node, as part of the Basque Digital Innovation Hub, thus provides the optimum ecosystem for this development.

- The new approach to the DT for the grinding industry involves the interaction between four layers, namely process simulation, advanced testing of materials, state-of-the-art process monitoring and finally, an easy-to-use open interface that can be transferred to SMEs.

- Fundamental process simulation must go a step further and become a useful tool, not only for a better understanding of complex physical phenomena, but to reduce process setup times and to eliminate trial-and-error strategies typical of the manufacturing industries. For the DT of the grinding process presented in this paper, DEM modeling has been considered as the optimum simulation method, given the characteristics of the abrasive wheel material.

- Process simulation only becomes realistic when it is fed with actual and reliable data. Therefore, further efforts must be made within the fields of mechanical testing of grinding wheels and process monitoring using advanced sensors. Extensive research work will need to be devoted to both issues in the coming years.

- The proposed DT is not a closed tool, instead it is open so that it can incorporate new technologies for data acquisition and processing, new types of mechanical tests, and of course, new wheel materials and machine capabilities. Still, the proposal will be valid, because it incorporates the key factors for the grinding process.

- Finally, the knowledge developed must be effectively transferred to SMEs. Since heavy fundamental models, which involve the use of complex programs and costly hardware are not feasible for workshops, the development of easy-to-use applications for process optimization is of primary importance. In this paper, an open platform is proposed that is capable of integrating the knowledge generated in the other layers, thus becoming the actual user interface of the DT.

Author Contributions: Conceptualization, J.A.S.; formal analysis, I.P. and R.L.; funding acquisition, R.L.; investigation, L.G.; project administration, J.A.S.; resources, R.L.; software, I.P.; supervision, J.A.S.; validation, R.L.; writing-review and editing, L.G. All authors have read and agreed to the published version of the manuscript.

Funding: The authors gratefully acknowledge the funding support received from the Spanish Ministry of Economy and Competitiveness and the FEDER operation program for funding the project "Scientific models and machine-tool advanced sensing techniques for efficient machining of precision components of Low-Pressure Turbines" (DPI2017-82239-P).

Acknowledgments: The authors gratefully acknowledge the Basque Digital Innovation Hub (BDIH) initiative of the Basque Government. The research work has been carried out in facilities of the Digital Grinding Node.

Conflicts of Interest: The authors declare no conflict of interest.

\section{References}

1. Savvy Data Sistems. Available online: https://www.savvydatasystems.com/es/inicio (accessed on 21 September 2020).

2. Eurostat-1. Available online: https:/ec.europa.eu/eurostat/statistics-explained/index.php/Manufacturing statistics_-_NACE_Rev._2 (accessed on 21 September 2020).

3. Eurostat-2. Available online: https://ec.europa.eu/eurostat/web/products-eurostat-news/-/DDN-20171024-1 (accessed on 21 September 2020).

4. CECIMO. Available online: https://www.cecimo.eu/wp-content/uploads/2019/03/CECIMO_Statistical_ Toolbox_3_2018.pdf (accessed on 21 September 2020).

5. EPMA. Available online: https://www.epma.com/dm-industry-news/833-eurofound-report-future-ofmanufacturing-in-europe-april-2019/file (accessed on 21 September 2020).

6. Pilloni, V. How data will transform industrial processes: Crowdsensing, crowdsourcing and big data as pillars of industry 4.0. Future Internet 2018, 10, 24. [CrossRef]

7. Klocke, F.; Soo, S.L.; Karpuschewski, B.; Webster, J.A.; Novovic, D.; Elfizy, A.; Axinte, D.A.; Tönissena, S. Abrasive machining of advanced aerospace alloys and composites. CIRP Ann. 2015, 64, 581-604. [CrossRef] 
8. Miao, Q.; Ding, W.; Kuang, W.; Yang, C. Comparison on grindability and surface integrity in creep feed grinding of GH4169, K403, DZ408 and DD6 nickel-based superalloys. J. Manuf. Process. 2020, 49, 175-186. [CrossRef]

9. Souza, A.M.; da Silva, E.J. Global strategy of grinding wheel performance evaluation applied to grinding of superalloys. Precis. Eng. 2019, 57, 113-126. [CrossRef]

10. Sustainable Development. Available online: https:/www.un.org/sustainabledevelopment/energy/ (accessed on 21 September 2020).

11. Global Grinding Wheels Sales Market Report 2019. 2019. Available online: https://www.giiresearch.com/ report/qyr458117-global-grinding-wheels-sales-market-report.html (accessed on 21 September 2020).

12. Lu, Y.; Liu, C.; Wang, K.I.-K.; Huang, H.; Xu, X. Digital Twin-driven smart manufacturing: Connotation, reference model, applications and research issues. Robot. Comput. Integr. Manuf. 2020, 61, 101837. [CrossRef]

13. Schleich, B.; Anwer, N.; Mathieu, L.; Wartzack, S. Shaping the digital twin for design and production engineering. CIRP Ann. 2017, 66, 141-144. [CrossRef]

14. Liu, Q.; Leng, J.; Yan, D.; Zhang, D.; Wei, L.; Yu, A.; Zhao, R.; Zhang, H.; Chen, X. Digital twin-based designing of the configuration, motion, control, and optimization model of a flow-type smart manufacturing system. J. Manuf. Syst. 2020. [CrossRef]

15. Huang, G.; Chen, J.; Khojasteh, Y. A cyber-physical system deployment based on pull strategies for one-of-a-kind production with limited resources. J. Intell. Manuf. 2020. [CrossRef]

16. Malkin, S. Thermal aspects of grinding Part 2: Surface Temperatures and Workpiece Burn. J. Eng. Ind. 1974, 96, 1184-1191. [CrossRef]

17. Snoeys, R.; Leuven, K.U.; Maris, M.; Wo, N.F.; Peter, J. Thermally induced damage in grinding. CIRP Ann. Manuf. Technol. 1978, 27, 141-144.

18. Lavine, A.S.; Malkin, S.; Jen, T.C. Thermal Aspects of Grinding with CBN Wheels. CIRP Ann. 1989, 38, 557-560. [CrossRef]

19. Lavine, A.S.; Jen, T.-C. Coupled heat transfer to workpiece, wheel, and fluid in grinding, and the occurrence of workpiece burn. Int. J. Heat Mass Transf. 1991, 34, 983-992. [CrossRef]

20. Ueda, T.; Sato, M.; Nakayama, K. Cooling Characteristics of Cutting Grain in Grinding. CIRP Ann. 1996, 45, 293-298. [CrossRef]

21. Rowe, W.B.; Morgan, M.N.; Qi, H.S.; Zheng, H.W. The Effect of Deformation on the Contact Area in Grinding. CIRP Ann. 1993, 42, 409-412. [CrossRef]

22. Rowe, W.B.; Black, S.C.E.; Mills, B.; Qi, H.S.; Morgan, M.N. Experimental Investigation of Heat Transfer in Grinding. CIRP Ann. 1995, 44, 329-332. [CrossRef]

23. Malkin, S.; Guo, C. Grinding Technology_Theory and Applications of Machining with Abrasives; Industrial Press Inc.: New York, NY, USA, 2008.

24. Wang, Z.; Yu, T.; Wang, X.; Zhang, T.; Zhao, J.; Wen, P.H. Grinding temperature field prediction by meshless finite block method with double infinite element. Int. J. Mech. Sci. 2019, 153-154, 131-142. [CrossRef]

25. Anderson, D.; Warkentin, A.; Bauer, R. Experimental and numerical investigations of single abrasive-grain cutting. Int. J. Mach. Tools Manuf. 2011, 51, 898-910. [CrossRef]

26. Zhang, Y.; Fang, C.; Huang, G.; Xu, X. Modeling and simulation of the distribution of undeformed chip thicknesses in surface grinding. Int. J. Mach. Tools Manuf. 2018, 127, 14-27. [CrossRef]

27. Pombo, I.; Cearsolo, X.; Sánchez, J.A.; Cabanes, I. Experimental and numerical analysis of thermal phenomena in the wear of single point diamond dressing tools. J. Manuf. Process. 2017, 27, 145-157. [CrossRef]

28. Liu, W.; Deng, Z.; Shang, Y.; Wan, L. Parametric evaluation and three-dimensional modelling for surface topography of grinding wheel. Int. J. Mech. Sci. 2019, 155, 334-342. [CrossRef]

29. Doman, D.A.; Warkentin, A.; Bauer, R. Finite element modeling approaches in grinding. Int. J. Mach. Tools Manuf. 2009, 49, 109-116. [CrossRef]

30. Klocke, F. Manufacturing Processes 2: Grinding, Honing and Lapping; Springer: Berlin/Heidelberg, Germany, 2009.

31. Matsuno, Y.; Yamada, H. Elastic moduli of grinding wheel based on a simplified model. J. Ceram. Assoc. Jpn. 1982, 90, 320-325. [CrossRef]

32. Tarokh, A.; Fakhimi, A. Discrete element simulation of the effect of particle size on the size of fracture process zone in quasi-brittle materials. Comput. Geotech. 2014, 62, 51-60. [CrossRef] 
33. Ma, Y.; Huang, H. A displacement-softening contact model for discrete element modeling of quasi-brittle materials. Int. J. Rock Mech. Min. Sci. 2018, 104, 9-19. [CrossRef]

34. André, D.; Girardot, J.; Hubert, C. A novel DEM approach for modeling brittle elastic media based on distinct lattice spring model. Comput. Methods Appl. Mech. Eng. 2019, 350, 100-122. [CrossRef]

35. Li, H.; Yu, T.; Zhu, L.; Wang, W. Modeling and simulation of grinding wheel by discrete element method and experimental validation. Int. J. Adv. Manuf. Technol. 2015, 81, 1921-1938. [CrossRef]

36. Li, H.; Yu, T.; Zhu, L.; Wang, W. Analysis of loads on grinding wheel binder in grinding process: Insights from discontinuum-hypothesis-based grinding simulation. Int. J. Adv. Manuf. Technol. 2015, 78, 1943-1960. [CrossRef]

37. Urgoiti, L.; Barrenetxea, D.; Sánchez, J.A.; Pombo, I.; Álvarez, J. On the influence of infra-red sensor in the accurate estimation of grinding temperatures. Sensors 2018, 18, 4134. [CrossRef]

38. Littman, W.E. The Influence of the Grinding Process on the Structure of Hardened Steel. Ph.D. Thesis, Massachusetts Institute of Technology, Cambridge, MA, USA, 1953.

39. Kohli, S.; Guo, C.; Malkin, S. Energy Partition to the Workpiece for Grinding with Aluminum Oxide and CBN Abrasive Wheels. J. Eng. Ind. 1995, 117, 160-168. [CrossRef]

40. Xu, X.P.; Yu, Y.Q.; Xu, H.J. Effect of grinding temperatures on the surface integrity of a nickel-based superalloy. J. Mater. Process. Technol. 2002, 129, 359-363. [CrossRef]

41. Lefebvre; Vieville, P.A.; Lipinski, P.; Lescalier, C. Numerical analysis of grinding temperature measurement by the foil/workpiece thermocouple method. Int. J. Mach. Tools Manuf. 2006, 46, 1716-1726. [CrossRef]

42. Davies, M.A.; Ueda, T.; M'Saoubi, R.; Mullany, B.; Cooke, A.L. On The Measurement of Temperature in Material Removal Processes. CIRP Ann. 2007, 56, 581-604. [CrossRef]

43. Baumgart, C.; Heizer, V.; Wegener, K. In-process workpiece based temperature measurement in cylindrical grinding. Procedia CIRP 2018, 77, 42-45. [CrossRef]

44. Brinksmeier, E.; Eckebrecht, J.; Wilkens, A. Wheel based temperature measurement in grinding. Adv. Mater. Res. 2011, 325, 3-11. [CrossRef]

45. He, B.; Wei, C.; Ding, S.; Shi, Z. A survey of methods for detecting metallic grinding burn. Measurement 2019, 134, 426-439. [CrossRef]

46. Teixeira, P.H.O.; Rego, R.R.; Pinto, F.W.; Gomes, J.d.; Löpenhaus, C. Application of Hall effect for assessing grinding thermal damage. J. Mater. Process. Technol. 2019, 270, 356-364. [CrossRef]

47. Oliveira, J.F.G.; Coelho, R.T.; Neto, C.K. Development of an Optical Scanner To Study Wear on the Working Surface of Grinding Wheels. Mach. Sci. Technol. 1999, 3, 239-253. [CrossRef]

48. Godino, L.; Pombo, I.; Sanchez, J.A.; Alvarez, J. On the development and evolution of wear flats in microcrystalline sintered alumina grinding wheels. J. Manuf. Process. 2018, 32, 494-505. [CrossRef]

49. Xu, L.; Niu, M.; Zhao, D.; Xing, N.; Fan, F. Methodology for the immediate detection and treatment of wheel wear in contour grinding. Precis. Eng. 2019, 60, 405-412. [CrossRef]

50. Lachance, S.; Bauer, R.; Warkentin, A. Application of region growing method to evaluate the surface condition of grinding wheels. Int. J. Mach. Tools Manuf. 2004, 44, 823-829. [CrossRef]

51. Nadolny, K. Wear phenomena of grinding wheels with sol-gel alumina abrasive grains and glass-ceramic vitrified bond during internal cylindrical traverse grinding of 100Cr6 steel. Int. J. Adv. Manuf. Technol. 2015, 77, 83-98. [CrossRef]

52. Miao, Q.; Ding, W.; Kuang, W.; Xu, J. Tool wear behavior of vitrified microcrystalline alumina wheels in creep feed profile grinding of turbine blade root of single crystal nickel-based superalloy. Tribol. Int. 2020, 145, 106144. [CrossRef]

53. Barrenetxea, D.; Marquinez, J.I.; Bediaga, I.; Uriarte, L. Continuous workpiece speed variation (CWSV): Model based practical application to avoid chatter in grinding. CIRP Ann. 2009, 58, 319-322. [CrossRef]

54. Ahrens, M.; Fischer, R.; Dagen, M.; Denkena, B.; Ortmaier, T. Abrasion Monitoring and Automatic Chatter Detection in Cylindrical Plunge Grinding. Procedia CIRP 2013, 8, 374-378. [CrossRef]

55. Yan, Y.; Xu, J.; Wiercigroch, M. Non-linear analysis and quench control of chatter in plunge grinding. Int. J. Non-Linear Mech. 2015, 70, 134-144. [CrossRef]

56. Liu, Y.; Wang, X.; Lin, J.; Kong, X. An adaptive grinding chatter detection method considering the chatter frequency shift characteristic. Mech. Syst. Signal Process. 2020, 142, 106672. [CrossRef]

57. Merino, R.; Barrenetxea, D.; Munoa, J.; Dombovari, Z. Analysis of the beating frequencies in dressing and its effect in surface waviness. CIRP Ann. 2019, 68, 353-356. [CrossRef] 
58. Jayakumar, T.; Mukhopadhyay, C.K.; Venugopal, S.; Mannan, S.L.; Raj, B. A review of the application of acoustic emission techniques for monitoring forming and grinding processes. J. Mater. Process. Technol. 2005, 159, 48-61. [CrossRef]

59. Badger, J.; Murphy, S.; O’Donnell, G.E. Acoustic emission in dressing of grinding wheels: AE intensity, dressing energy, and quantification of dressing sharpness and increase in diamond wear-flat size. Int. J. Mach. Tools Manuf. 2018, 125, 11-19. [CrossRef]

60. Yang, Z.; Yu, Z.; Xie, C.; Huang, Y. Application of Hilbert-Huang Transform to acoustic emission signal for burn feature extraction in surface grinding process. Measurement 2014, 47, 14-21. [CrossRef]

61. Kannan, K.; Arunachalam, N. A Digital Twin for Grinding Wheel: An Information Sharing Platform for Sustainable Grinding Process. J. Manuf. Sci. Eng. 2019, 141. [CrossRef]

62. André, D.; Iordanoff, I.; Charles, J.L.; Néauport, J. Discrete element method to simulate continuous material by using the cohesive beam model. Comput. Methods Appl. Mech. Eng. 2012, 213-216, 113-125. [CrossRef]

63. Osa, J.L.; Sánchez, J.A.; Ortega, N.; Iordanoff, I.; Charles, J.L. Discrete-element modelling of the grinding contact length combining the wheel-body structure and the surface-topography models. Int. J. Mach. Tools Manuf. 2016, 110, 43-54. [CrossRef]

64. Godino, L.; Pombo, I.; Girardot, J.; Sanchez, J.A.; Iordanoff, I. Modelling the wear evolution of a single alumina abrasive grain: Analyzing the influence of crystalline structure. J. Mater. Process. Technol. 2020, 277, 116464. [CrossRef]

(C) 2020 by the authors. Licensee MDPI, Basel, Switzerland. This article is an open access article distributed under the terms and conditions of the Creative Commons Attribution (CC BY) license (http://creativecommons.org/licenses/by/4.0/). 